\title{
Fabrication of Xanthan gum: Gelatin (Xnt:Gel) Hybrid Composite Hydrogels for Evaluating Skin Wound Healing Efficacy
}

\author{
Mohammad Mahfuz Ali Khan Shawan ${ }^{1}$, Nazmul Islam ${ }^{1}$, Shahin Aziz², Nazia Khatun², Satya Ranjan Sarker ${ }^{3}$, \\ Mozammel Hossain ${ }^{1}$, Tareq Hossan ${ }^{1}$, Mahbubul Morshed ${ }^{1}$, Marzan Sarkar ${ }^{1}$, Md. Salman Shakil ${ }^{1}$, Md. Nazibur \\ Rahman $^{1}$, Most. Hosney Ara Begum² \& Md. Ashraful Hasan ${ }^{1}$ \\ ${ }^{1}$ Department of Biochemistry and Molecular Biology, Jahangirnagar University, Savar, Dhaka-1342, Bangladesh \\ ${ }^{2}$ BCSIR Laboratories, BCSIR, Dhaka, Bangladesh, Bangladesh Council for Scientific and Industrial Research, \\ Shahbag, Dhaka -1000, Bangladesh \\ ${ }^{3}$ Department of Biotechnology and Genetic Engineering, Jahangirnagar University, Savar, Dhaka-1342, \\ Bangladesh \\ Correspondence: Md. Ashraful Hasan, Department of Biochemistry and Molecular Biology, Jahangirnagar \\ University, Savar, Dhaka-1342, Bangladesh. E-mail address: ashrafulhasan@juniv.edu\& Most. Hosney Ara \\ Begum, BCSIR Laboratories, BCSIR, Dhaka, Bangladesh, Bangladesh Council for Scientific and Industrial \\ Research, Shahbag, Dhaka -1000, Bangladesh. E-mail: hosneyara@gmail.com
}

Received: December 5, 2018

Accepted: December 17, 2018

Online Published: February 25, 2019

doi:10.5539/mas.v13n3p101

URL: https://doi.org/10.5539/mas.v13n3p101

\begin{abstract}
With the background of snowballing threat of skin wound to public health and economy, this study was undertaken utilizing xanthan gum (Xnt), citric acid (C), gelatin (Gel), glutaraldehyde (G) and HPLC-grade water to fabricate a series of composite hydrogels i.e. Xnt, Xnt:C, Xnt:Gel(3):G, Xnt:C:Gel(3):G, Xnt:Gel(5):G, Xnt:C:Gel(5):G for investigating their wound healing efficacy in experimental rat skin wound model. Physicochemical characterization revealed that all the composite hydrogels contained more than $90 \%$ water. The hydrogels displayed swelling ability, biodegradability, good polymeric networks and porosity. Fourier Transform Infrared Spectroscopy (FT-IR) studies confirmed the presence of bound water and free, intra and inter molecular bound hydrogen bonded $\mathrm{OH}$ and $\mathrm{NH}$ in the hydrogels. All the hydrogels showed significant wound healing potency in experimental deep second degree skin burns in rats compared to controls. 20 days post-application of hydrogels, Xnt:Gel(3):G, Xnt:Gel(5):G and Xnt:C:Gel(5):G-treated wounds showed better recovery compared to other composite hydrogels. We conclude that, Xnt:Gel(3):G, Xnt:Gel(5):G and Xnt:C:Gel(5):G might be effective wound dressing material.
\end{abstract}

Keywords: xanthan gum, gelatin, hydrogels, skin wound healing

\section{Introduction}

A wound is regarded as a breakage or disruption in the integrity of the epithelial lining of the skin or mucosa which is formed due to physical or thermal damage and may be accompanied by disruption of the structure and function of underlying normal tissue (Kamoun, 2017 \& Gupta, 2011). Wounds impose a substantial health economic burden on the health service. In UK, the total annual NHS cost of managing healed wounds and unhealed wounds was estimated to be $£ 2.0$ billion and $£ 3.0$ billion, respectively (Guest, 2017 \& Gupta, 2011). Wounds are more susceptible to infection and other troublesome complications (Cartotto, 2017; Gupta, 2011 \& Meyer-Ingold, 1993). Wound infection induces body's immune response causing inflammation and tissue damage resulting in delay in the healing process (Cartotto, 2017). Some chronic diseases such as diabetes, ischemia also cause delay in wound healing (Gupta, 2011). Thus, a potential dressing system with lower cost expenditure that may facilitate faster wound healing is of greater interest due to the threats associated with wound.

A major limitation of the current commercial dressings such as membranes and sheets is their conformability on wound (Fan, 2013). Another critical limitation of some commercial wound dressing is the possession of antimicrobial agents which might exert cytotoxic effects on long term administration leading to delayed wound healing (Cartotto, 2017 \& El-Kased, 2017). A study conducted by Winter et al demonstrated that moist wound healing rate is faster than dry wound (Winter, 1962).Moist environment, however, is not ideally maintained by the 
current wound dressing systems. A large number of the marketed dressings lose their moisturizing effect, which make them adhere to the surface of the wound and damage the newly formed epithelium (Maden, 2018 \& ElKased, 2017).

Hydrogels are cross-linked, three dimensional, hydrophilic polymeric networks with the ability to hold large amount of water within its porous structure (Rithe, 2014; El-Sherbiny and Yacoub, 2013; Chavda, 2012; Ray, 2010 $\& \mathrm{Pal}, 2009$ ). However, they do not dissolve in water when brought into contact with water (Rithe, 2014; ElSherbiny and Yacoub, 2013; Chavda, 2012; Ray, 2010 \& Pal, 2009). The water holding capacity of hydrogels is induced by the presence of hydrophilic groups, such as hydroxyl, carboxyl, amide, and sulfonic groups distributed along the backbone of polymer chain; whereas the cross-links are formed by either covalent bonds, electrostatic or dipole-dipole interactions (Rithe, 2014; El-Sherbiny and Yacoub, 2013; Chavda, 2012; Ray, 2010 \& Pal, 2009).Hydrogels have achieved considerable interest in the last few decades due to their wide range of clinical and biomedical applications ranging from drug delivery (Qui and Park, 2001), tissue engineering (El-Sherbiny and Yacoub, 2013; Vlierberghe, 2011 \&Hoffman, 2002),regenerative medicine (El-Sherbiny and Yacoub, 2013), contact lenses (Walther, 2011 \& Zhang, 2011), wound dressings (El-Kased, 2017; Gupta, 2011 \& Lu, 2010), soil water retention (Wei and Durian, 2013) to disposable diapers (Colón, 2011).

While considering the role of hydrogels in wound dressing, they have the advantages like possessing the features of moist wound healing with good fluid absorbance (Weller, 2009). Furthermore, in situ forming hydrogels that mould into the shape of wound defect would enable conformability of the dressing on wounds without wrinkling or fluting (Fan, 2013). Due to their three dimensional structure, biodegradability, biocompatibility, and ability to generate a favorable microenvironment for cell growth and/or differentiation, hydrogels attain attraction as suitable candidates for wound dressing in recent years (Fan, 2013; Gupta, 2011; Varghese, 2008 \& Varghese, 2000).

Xanthan gum (Xnt) is a high molecular weight anionic heteropolysaccharide composed of $(1,4)-\beta$-D-glucose residues as the backbone at which a trisaccharide side chain is linked at $\mathrm{C} 3$ position to alternate glucose residues (Brunchi, 2016 \& Fitzpatrick, 2013). Trisaccharide side chains are composed of mannose, glucuronic acid and mannose linked by $\beta-1,2$ and $\beta-1,4$ glycosidic bond (Brunchi, 2016 \& Fitzpatrick, 2013).Approximately half of the terminal mannose residues are linked to pyruvic acid moieties by ketal linkage, while acetyl groups are often present as 6-O substituents on the internal mannose residues (Brunchi, 2016 \& Fitzpatrick, 2013).Xnt is used as thickening, suspending, and emulsifying agents in pharmaceutics (Karadağ, 2015 \& Davidson, 1980). It has been used in the hydrophilic matrix formulations for controlled drug release, and it also has applications as a supporting material in enzyme and cell immobilization (Karadağ, 2015; Bhunia, 2013; Bhattacharya, 2012; Ray, 2010; Alupei, 2002; García-Ochoa, 2000 \& Davidson, 1980). It was used in the preparation of a biodegradable hydrogels for skin scaffold (Juris, 2011). A study of Bueno et al. previously showed the swelling behaviour of Xnt hydrogels (Bueno, 2013).

Gelatin (Gel) obtained from partially hydrolyzing collagen is biocompatible, biodegradable and has a high hemostatic effect (Wu, 2017 \& Lee, 2003). Biodegradability of Gel due to its matrix metalloproteinase (MMP) sensitive protein sequences is usually a desirable biomaterial property for in vivo implanted hydrogels because scaffold degradation enables deposition and formation of new tissue (Camci-Unal, 2013). Several beneficial effects of Gel have been reported in the previous studies. Gel facilitates the process of tissue regeneration by promoting cellular behavior such as migration, adhesion, and the growth of cells (Wu, 2017; Pezeshki-Modaress, 2015; Li, 2014 \& Pezeshki-Modaress, 2014).Gel can speed up the process of granulation and epithelialization as well as macrophage activation without antigenicity (Wu, 2017 \& Choi, 1999).Furthermore, Gel has been utilized for the deliveries of a number of small molecules (Wu, 2017; Kommareddy and Amiji, 2005 \& Kimura, 2003). Since it has great biological advantages and is low in cost, Gel has been widely used in the medical field (Wu, 2017; Liu, 2007; Kommareddy and Amiji, 2005 \& Kimura, 2003). However, the limitation of Gel hydrogels is their mechanical weakness and quick degradation behavior (Camci-Unal, 2013). Severe swelling after absorbance of water is considered as a drawback for Gel hydrogels for its application as wound scaffold since the deformation after severe swelling will make the dressings unable to maintain the structure of the dressings and conformability to the wound will not be maintained ( $\mathrm{Wu}, 2017)$.

Fabrication of hybrid hydrogels to improve biological properties or to decrease the disadvantages of biomaterials has been a popular approach. Previously, efficacy of fabricated hyaluronic acid:gelatin hybrid hydrogel in animal wound model was investigated (Wu, 2017).Though different beneficial effects of Xnt and Gel have been demonstrated previously,it is yet to report about the fabrication and characterization of Xnt:Gel hybrid hydrogel and evaluation of its efficacy in wound healing. In this study, for the first time, we have fabricated a series of Xnt:Gel hybrid hydrogels, characterized them and evaluated their efficacy in experimental second degree skin burns in rats. 


\section{Materials and Methods}

\subsection{Materials}

For the preparation of Xnt:Gel-based hydrogels, we used Xnt, Gel, citric acid (C), glutaraldehyde (G) and HPLCgrade water. Xnt was obtained from Zhengzhou Sino Chemical Co. Ltd., while Gel, C and G were purchased from Sigma Aldrich. HPLC-grade water was prepared in the laboratory. All chemicals and polymeric materials were used as obtained without any purification or modification.

\subsection{Preparation of Hydrogels}

For the preparation of hydrogels with different compositions, all the chemicals (Xnt, Gel, C and G) with different proportions (Table 1) were dispersed in HPLC-grade water. Afterwards, the mixture was stirred and heated to $85^{\circ}$ $\mathrm{C}$ to initiate gelling and reweighed to measure the loss of water through evaporation from sample mixture. The water lost during heating was re-added to the mixture, which was again heated to $85^{\circ} \mathrm{C}$ until the gel was formed. Gel should be free from entrapped air. The gel was then poured into petri dishes and allowed to cool at room temperature to obtain polymeric hydrogel. Then prepared hydrogels were preserved at $4^{\circ} \mathrm{C}$.

Table 1. Composition of hydrogel composites

\begin{tabular}{lllllll}
\hline $\begin{array}{l}\text { Hydrogel } \\
\text { Sample }\end{array}$ & Nomenclature & $\begin{array}{l}\text { Xanthan gum } \\
(\mathrm{mg})\end{array}$ & $\begin{array}{l}\text { Citric Acid } \\
(\mathrm{mg})\end{array}$ & $\begin{array}{l}\text { Gelatin } \\
(\mathrm{mg})\end{array}$ & $\begin{array}{l}\text { Glutaraldehyde } \\
(\mathrm{ml})\end{array}$ & $\begin{array}{l}\text { HPLC water } \\
(\mathrm{ml})\end{array}$ \\
\hline 1 & Xnt & 600 & - & - & - & 100 \\
2 & Xnt:C & 600 & 30 & - & - & 100 \\
3 & Xnt:Gel(3):G & 600 & - & 3 & 0.5 & 99.5 \\
4 & Xnt:C:Gel(3):G & 600 & 30 & 3 & 0.5 & 99.5 \\
5 & Xnt:Gel(5):G & 600 & 30 & 5 & 0.5 & 99.5 \\
6 & Xnt:C:Gel(5):G & 600 & 30 & 5 & 0.5 & 99.5 \\
\hline
\end{tabular}

\subsection{Determination of Moisture Content of Hydrogels}

Moisture content of the prepared hydrogels was determined as described previously with minor modifications (Rithe, 2014). Briefly, 2 gm of sample was weighed in a clean porcelain pot and heated in a temperature controlled water bath for about six hours at $105^{\circ} \mathrm{C}$. It was then cooled in desiccators and weighed again. The moisture percentage in hydrogels was calculated from the following formula:

Moisture percentage $=100\{(\mathrm{~W} 1-\mathrm{W} 2) / \mathrm{W} 1\} \%$

Here, $\mathrm{W} 1=$ original weight of the sample before drying and $\mathrm{W} 2$ = weight of the sample after drying.

\subsection{Swelling measurement of hydrogels}

The swelling was measured as described previously (Karadağ, 2015). The dry gel was immersed in HPLC water for $16 \mathrm{~h}$ at room temperature. The swelling ratio $(S)$ of the hydrogels in distilled water was calculated from the following relation:

$$
S=\left(\mathrm{m}_{\mathrm{t}}-\mathrm{m}_{0}\right) / \mathrm{m}_{0}
$$

Here, $\mathrm{m}_{\mathrm{t}}$ is the mass of the swollen gel at time $\mathrm{t}$ and $\mathrm{m}_{0}$ is the mass of the dry gel at time 0 .

\subsection{Biodegradability of hydrogels}

Biodegradability of hydrogels was measured as described previously with minor modifications (Guan, 2005). In brief, samples were dried to a constant weight before initial weighing. Hydrogels were fully immersed in the physiological solution for a specified period of time (for example 1 week, 2 weeks, 3 weeks etc.). Upon completion of the specified time period, each sample was removed and dried to a constant weight. After weighing, the samples were not returned to the physiological solution and were retired from the study.

\subsection{Fourier Transform Infrared (FT-IR) studies}

The hydrogel preparations were dried and converted to powdered form for FT-IR study. The powdered samples were mixed with $\mathrm{KBr}$ and FT-IR spectrum was recorded over the range $600-4000 \mathrm{~cm}^{-1}$ using FT-IR- $8400 \mathrm{~S}$ Spectrometer (Shimadzu, Japan).

\subsection{Scanning electron microscopy (SEM) studies}

The structural morphology of hydrogel was analyzed by scanning electron microscopy (SEM) to ensure that 
hydrogel retains its structure. The desiccated hydrogels were cut to expose their inner structure and used for SEM studies. The morphology and porous structure of the hydrogel was examined using HITACHI S3400N SEM with an operating voltage of $15 \mathrm{kV}$.

\subsection{In vivo wound healing}

The experiment was carried out using adult male albino Wister rats aged between 6 to 7 weeks and weighing between 150 to $170 \mathrm{~g}$. Albino Wister rats were bred and reared in the animal house facility of the Department of Biochemistry and Molecular Biology, Jahangirnagar University at a constant room temperature of $25 \pm 2^{\circ} \mathrm{C}$ and at humidity between $40 \%$ and $70 \%$. The rats were housed in plastic cages (bedding was hardwood chips) and in polypropylene cages and received a natural $12 \mathrm{~h}$ day - night cycle. The rats were provided with a standard laboratory pellet diet and water. The experiments were conducted in accordance with the guidelines for the care and use of laboratory animals and approved by the Biosafety, Biosecurity and Ethical Committee of Jahangirnagar University, Savar, Dhaka, Bangladesh. The skin of the animal was shaved and disinfected using $70 \%$ ethanol. The burn wounds were created using the method described previously with some modifications (Rozaini, 2004). A cylindrical metal rod $\left(10 \mathrm{~mm}\right.$ diameter) was heated into boiled water at $99-101^{\circ} \mathrm{C}$ over the open flame for 1 minute and pressed to the shaved and disinfected surface for $30 \mathrm{sec}$ in rat under light ketamine anesthesia.

\subsection{Measurement of wound area}

The progressive changes in wound area were measured in $\mathrm{mm}^{2}$ by tracing the wound boundaries on a transparent paper on every 5-day interval. The wound areas in all groups were recorded on a graph paper. Wound size on different days was expressed in percentage of the original wound size.

\subsection{Statistical analysis}

All data were analyzed by GraphPad Prism 5.0 (GraphPad software) and Microsoft excel. All data are presented as means \pm S.E.M from at least three independent experiments. Bonferroni test was used for post-hoc comparison. $\mathrm{p}<0.05$ was considered to indicate statistical significance.

\section{Results and Discussions}

\subsection{Moisture Content}

An important characteristic of hydrogels is the ability to contain large amounts of water together with maintaining their dimensional stability (Patel and Mequanint, 2011). Moisture content supports the integrity of hydrogels (Vladimir, 2017; Jayakumar, 2010 \& Jayakumar, 2010).Furthermore, the solubility and diffusion of substances are important for biomedical applications, which are facilitated by the moisture content of hydrogels (Vladimir, 2017). The water content of hydrogel may also affect hydrogel volume due to swelling/shrinking influenced by external conditions, such as temperature, $\mathrm{pH}$, ionic strength, solvent nature, etc (Vladimir, 2017).

Moisture content values obtained for the prepared hydrogels is plotted in Figure 1. It is evident from Figure 1 that, all the hydrogels contained more than $90 \%$ water, indicating their effectiveness to donate water to the wound site and thus help in maintaining a moist environment, which helps in faster wound healing. In this study, Xnt was a common ingredient in all the composite hydrogels. Xnt contains hydrophilic groups such as $-\mathrm{COO},-\mathrm{OH}$ etc. Other ingredients used in different composite hydrogels were C, Gel and G. Gel also contains different hydrophilic groups such as $-\mathrm{COO}$ and $-\mathrm{NH}_{2}$ etc. $\mathrm{C}$ contains $-\mathrm{COO}$ and $-\mathrm{OH}$, while $\mathrm{G}$ contains $-\mathrm{CHO}$ and $-\mathrm{COO}$ in its structure The moisture content of different hybrid composite hydrogels is attributed to the hydrophilic groups present in these hydrogels.

\subsection{Swelling Test of Hydrogels}

Swelling characteristics of hydrogels are important while using as moist wound dressing. Swelling capabilities of hydrogels indicate its ability to absorb a degree of wound exudates and to maintain moist environment at the wound site (Gupta, 2011). As shown from Figure 2, swelling ratio ranged from $4.83 \pm 0.12$ to $7.03 \pm 0.06$ in all the hydrogels indicating their efficacy for application as wound dressing material. Hydrogels prepared from only Xnt showed a swelling ratio of $7.03 \pm 0.06$. When $\mathrm{C}$ was used in the formulation (i.e. Xnt:C), swelling ratio significantly decreased to $4.86 \pm 0.08$ ( $<<0.05)$. Notably, crosslinking density is inversely proportional to swelling capacity (Juris, 2011 \& Huglin, 1986). Furthermore, it is an indication of the degree of hydrophilicity of the hydrogels (Camci-Unal, 2013). Our finding is consistent with this observation. Pure Xnt chains have limited number of groups that can be crosslinked (Juris, 2011). Previous study demonstrated that $C$ promotes esterification cross-linking in the Xnt (Juris, 2011).Thus, it is assumed that because of the cross-linking in presence of C, swelling ability of Xnt:C hydrogel decreased. Xnt when, however, was reacted with $3 \mathrm{mg}$ Gel and $\mathrm{G}$ to form hydrogel i.e. Xnt:Gel(3):G, swelling ability of the formulation, though nonsignificant, minutely decreased to 6.53 
\pm 0.33 (Xnt vs Xnt:Gel(3):G; p not <0.05). Gel alone can absorb huge amount of water (Wu, 2017). The minute decrease in the swelling capacity of Xnt:Gel(3):G hybrid hydrogel, however, is probably due to the combined effect of increased cross-linking in the hydrogel in presence of Gel and G along with its hydrophilicity. This is in line with the observation that, concentration-dependent increase in Gel (i.e. $3 \mathrm{mg}$ to $5 \mathrm{mg}$ ) in the formulation (i.e Xnt:Gel(5):G) resulted in further minute decrease in the swelling capacity (i.e $5.96 \pm 0.57$ ) of the hydrogel. This observation indicates that cross-linking density might be increased with the increased concentration of Gel. When $\mathrm{C}$ was added in the combination, swelling capacity of the hydrogel composite (i.e. Xnt:C:Gel(3):G) markedly decreased to $4.83 \pm 0.12$ (Xnt:Gel(3):G vs Xnt:C:Gel(3):G; $<<0.05$ ). Notably, swelling capacity of the hydrogels Xnt:C and Xnt:C:Gel(3):G was similar (i.e. $4.86 \pm 0.08$ and $4.83 \pm 0.12$, respectively; p not $<0.05$ ). Thus, presence of Gel and Glu in the combination Xnt:C:Gel(3):G did not affect its swelling capability. C significantly increases the cross-linking density of Xnt (Juris, 2011). So, it is assumable that, presence of Gel and Glu might not affect significantly to the cross-linking density of the hybrid hydrogel Xnt:C:Gel(3):G. However, increase in the Gel concentration in the combination Xnt:C:Gel(5):G showed minute increase in the swelling ability i.e $5.26 \pm 0.75$, presumably because of the hydrophilic group present in the Gel.

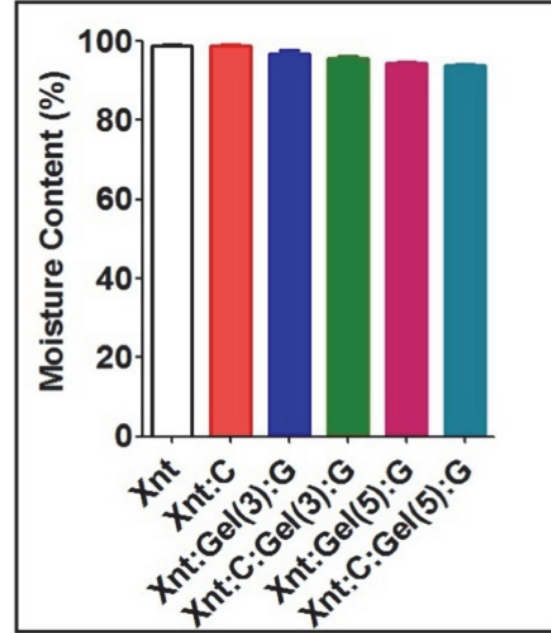

Figure 1. Moisture content of hydrogel composites

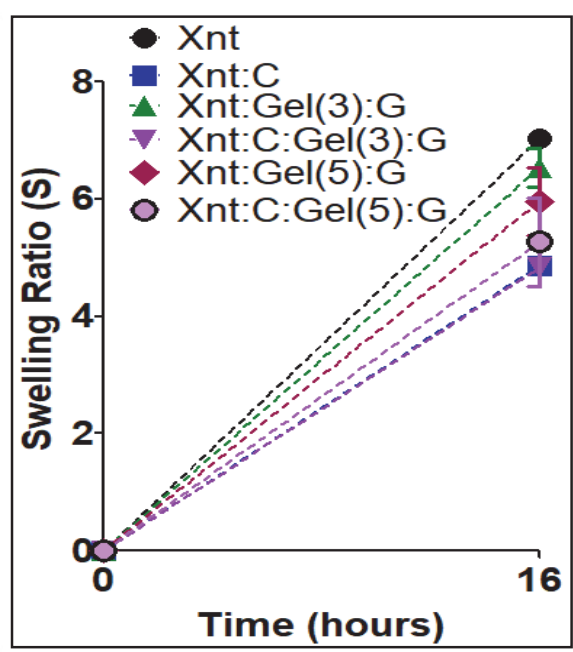

Figure 2. Swelling ability of of hydrogel composites

\subsection{Determination of Biodegradability}

For promoting wound healing, biodegradability is a major property of hydrogel since it fastens the tissue regeneration and excludes the necessity of a surgical removal (Camci-Unal, 2013; Gu, 2010; Schmidt and Leach, 2003 \& Langer and Vacanti, 1993). To assess how polymer composition alters degradation behaviour, we studied degradation behaviour of the synthesized hydrogels (Figure 3). Previous study revealed that degradation of Xnt hydrogel decreases with the increase of polymer concentration (Disha, 2016). In the present study, we observed that all the hydrogel composites showed biodegradability with the possession of weight ranging from $33.33 \pm 2.20 \%$ to $48.33 \pm 1.66 \%$ of its initial weight after 21 days (Figure 3). Hydrogel prepared from only Xnt possessed 33.33 $\pm 2.20 \%$ weights after 21 days. Notably, addition of $\mathrm{C}$ in the hydrogel preparation resulted in the decrease in degradation (i.e. weight remaining $43.33 \pm 0.83 \%$ in Xnt:C hydrogel vs $33.33 \pm 2.20 \%$ in Xnt hydrogel after 21 days; $\mathrm{p}<0.05$ ). Presence of Gel:G in the Xnt:Gel:G hydrogel minutely decreased the degradation rate compared to Xnt hydrogel. As is evident from Figure 3, after 21 days weight of Xnt:Gel:G hydrogel was $36.66 \pm 2.20 \%$ of its initial weight, while in Xnt hydrogel weight remained $33.33 \pm 2.20 \%$ of its initial weight ( $p$ not $<0.05$ ). The limitation of Gel hydrogels is their mechanical weakness and quick degradation behavior (Camci-Unal, 2013). Thus, degradation property of Gel can be avoided and advantageous property can be utilized using it in the Xnt:Gel:G hybrid hydrogel. Notably, degradation behaviour of Xnt:C and Xnt:C:Gel(3):G was similar (i.e. weight remaining after 21 days was $43.33 \pm 0.83 \%$ in Xnt:C vs $43.33 \pm 2.20 \%$ in Xnt:C:Gel(3):G; p not $<0.05)$. Presence of Gel (3mg) and G in the Xnt:C:Gel(3):G did not change the degradation behavior. However, presence of Gel (5mg) and G in the Xnt:C:Gel(5):G hydrogel showed a tendency to decrease the degradation (i.e. weight remaining after 21 days was $43.33 \pm 0.83 \%$ in Xnt:C vs $48.33 \pm 1.66 \%$ in Xnt:C:Gel(3):Glu; p not $<0.05)$, which might be due to the higher Gel concentration i.e $5 \mathrm{mg}$ and cross-linking density.

\subsection{Morphological Studies (SEM) of Hydrogels}

Figure 4 shows the microscopic morphology of the hydrogel compositions. As is evident from Figure 4, all the 
hydrogels show good polymeric networks and good porosity. The hydrogel surface appears smooth and thick, and is predominantly homogenous. Notably, porosity affects diffusion of nutrients and oxygen, especially in the absence of a functional vascular system. Thus, porosity observed in our hydrogels indicates its effectiveness to exert beneficial effects on wound healing.

\subsection{Fourier Transform Infrared Spectroscopy (FT-IR) Studies}

Figure 5 shows the FT-IR spectroscopy of the prepared hydrogels. In the spectra, the peaks at $1404-1500 \mathrm{~cm}^{-1}$ are due to $\mathrm{OH}$ bending and $\mathrm{C}-\mathrm{N}$ stretching. The peaks at $1625-1630 \mathrm{~cm}^{-1}$ are due to the bound water present in the xanthan gum and due to the stretching vibration of $-\mathrm{COO}$ of ester bonds. A broad band due to hydrogen bonded hydroxyl group $(\mathrm{O}-\mathrm{H})$ and $\mathrm{N}-\mathrm{H}$ group appeared at $3420-3434 \mathrm{~cm}^{-1}$ and is attributed to the complex vibrational stretching associated with free, intra and inter molecular bound hydroxyl group and $\mathrm{NH}$ stretching vibration due to $\mathrm{H}$ bonded $\mathrm{NH}$. The $\mathrm{C}-\mathrm{O}$ stretching strong modes have their characteristics peaks in the range $1400-100 \mathrm{~cm}^{-1}$. It is clear that there are multiple peaks between two spectra. Within the range $1000-500 \mathrm{~cm}^{-1}$, there are almost similar absorption peaks in these spectra. Peak $400-600 \mathrm{~cm}^{-1}$ is called signature pick.

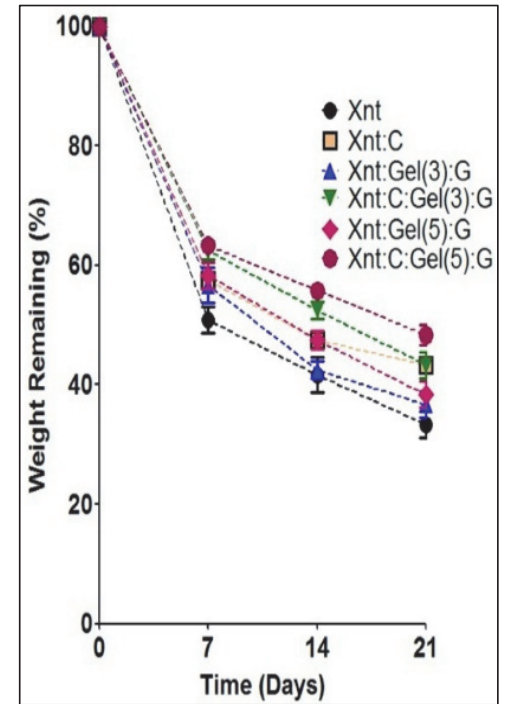

Figure 3. Biodegradability of hydrogel composites
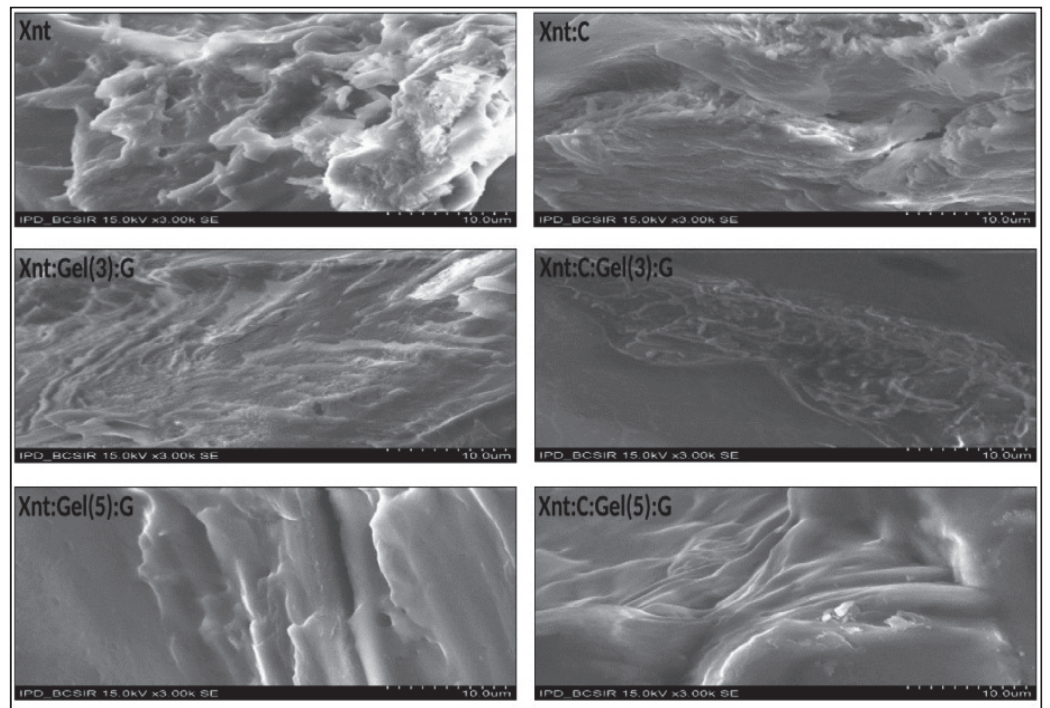

Figure 4. Surface morphology of the of hydrogel composites as determined by SEM 


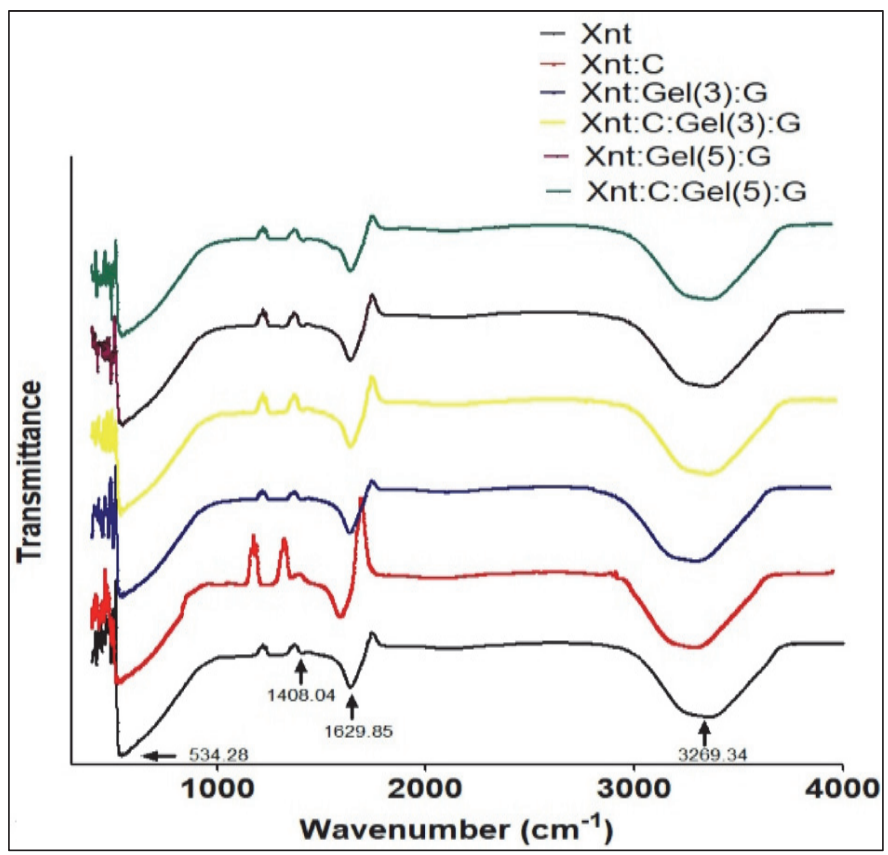

Figure 5. FTIR spectra of of hydrogel composites

\subsection{Wound Contraction Rate Measurement}

We investigated wound healing efficacy of the composite hydrogels in burn wound model in Wister rats. For creating burn wounds, the method described previously (Rozaini, 2004) with some modifications was followed. A cylindrical metal rod ( $10 \mathrm{~mm}$ diameter) was heated for 1 minute into boiled water at $99^{\circ}-101^{\circ} \mathrm{C}$ over the open flame and pressed to the shaved and disinfected dorsal surface for $30 \mathrm{sec}$ in rat under light ketamine anesthesia. We observed wounds of each group for a period of 5, 10, 15 and 20 days following application of the hydrogels to the wound site. After five days, skin appeared hemorrhagic for the control and test samples and there was no evidence of infection or contraction of the wound (Figure 6). It is evident from figure 6 and 7 that, all the composite hydrogels-treated wounds showed faster wound contraction rate compared to controls 15 days post treatment of hydrogels to the wound site $(\mathrm{p}<0.05)$. Wound size was reduced to at least $49.86 \pm 0.022 \%$ of its initial size in the hydrogel-treated groups compared to $73.91159 \pm 0.10 \%$ in the control. In a landmark article, Winter showed that epithelialisation of the wound occurs more quickly if a moist wound environment is maintained (Winter, 1962). In this article, Winter reported that, epithelization is retarded by the dry scab which normally covers a superficial wound, and if the formation of the scab is prevented, the rate of epithelization is markedly increased.One explanation for this was that keratinocytes migrated more easily over a moist wound surface than underneath a dry one (Winter and Scales, 1963).Epidermal cells can migrate at a speed of about $0.5 \mathrm{~mm} /$ day over a moist wound surface which is twice as fast as under a scab in dry wounds (Winter, 1972).Moist wound healing not only facilitates fragile epithelial cells to migrate more freely it also enhances viability of the epithelial cells as the cells are protected from dehydration and scab formation (Weller and Sussman, 2006). It is evident from figure $1 \& 2$ that, all the composite hydrogels contain more than $90 \%$ water and has remarkable swelling capabilities. Thus, it is plausible that they can maintain moist environment at the wound site. Notably, 20 days post-application of hydrogels, XNT:Gel(3):G, XNT:Gel(5):G and XNT:C:Gel(5):G-treated wounds showed highest recovery compared to other composite hydrogels $(\mathrm{p}<0.05)$. The highest wound contraction of these hydrogel composites might be due to presence of Gel in the formulations. Beneficial role of Gel in tissue regeneration have been reported in the previous studies. Gel promotes cellular behavior such as migration, adhesion, and the growth of cells by facilitating the process of tissue regeneration (Wu, 2017; Pezeshki-Modaress, 2015; Li, 2014 \& PezeshkiModaress, 2014).Gel without antigenicity can speed up the process of granulation and epithelialization and macrophage activation (Wu, 2017 \& Choi, 1999).Mechanical weakness, severe swelling after absorbance of water and quick degradation behavior is considered as a drawback for Gel hydrogels for its application as wound scaffold since the deformation after severe swelling will make the dressings unable to maintain the structure of the dressings and conformability to the wound will not be maintained (Wu, 2017 \& Camci-Unal, 2013). Thus, it is plausible that stability of Gel is better maintained and beneficial effect of tissue regeneration is better exploited while being part 
as an ingredient of the Xnt:Gel(3):G, Xnt:Gel(5):G and Xnt:C:Gel(5):G resulting in potential wound healing compared to other hydrogel composites.

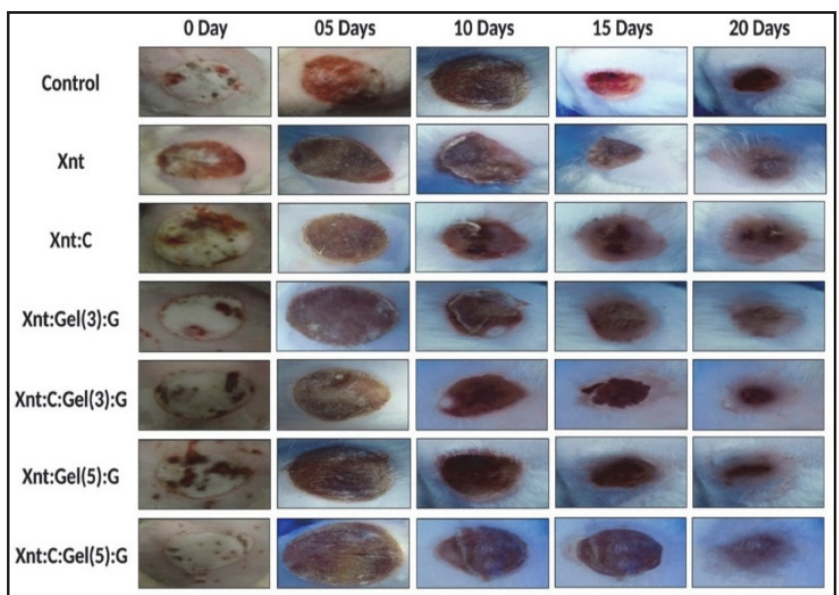

Figure 6 . Wound healing following application of of hydrogel composites in experimental deep second degree skin burns in rats

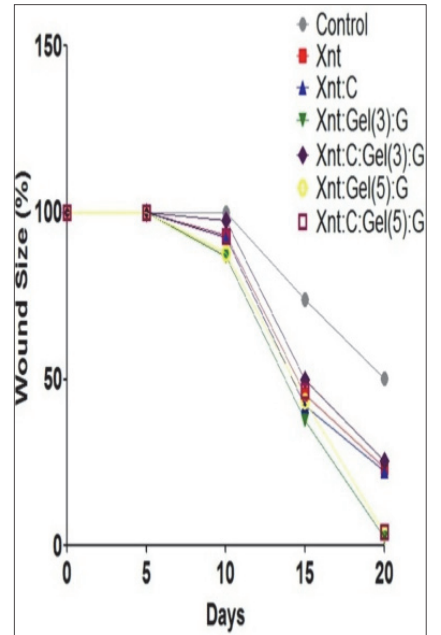

Figure 7. Wound size following application of hydrogel composites

\section{Conclusion}

To the best of our knowledge, this is the first study to show the effect of Xnt:Gel hybrid composite hydrogels in experimental skin burn wound in rats. In this study, Xnt, C, Gel, G and HPLC-grade water were utilized to fabricate a series of hybrid composite hydrogels i.e. Xnt, Xnt:C, Xnt:Gel(3):G, Xnt:C:Gel(3):G, Xnt:Gel(5):G, Xnt:C:Gel(5):G. Moisture content was more $90 \%$ in all the fabricated hybrid hydrogels while swelling score ranged from $4.83 \pm 0.12$ to $7.03 \pm 0.06$. Biodegradability of the hydrogels was revealed with the possession of weight ranging from $33.33 \pm 2.20 \%$ to $48.33 \pm 1.66 \%$ of its initial weight after 21 days. FT-IR studies confirmed the presence of bound water and free, intra and inter molecular bound hydrogen bonded $\mathrm{OH}$ and NH. Scanning electron microscopy revealed good polymeric networks and good porosity of the hydrogels. All the hydrogels displayed good wound healing potency. 20 days post-application of hydrogels, Xnt:Gel(3):G, Xnt:Gel(5):G, and Xnt:C:Gel(5):G treated wounds showed highest recovery compared to other hydrogel compositions. The highest wound contraction of these hydrogel composites might be due to presence of Gel in the formulations. We conclude that Xnt:Gel(3):G, Xnt:Gel(5):G and Xnt:C:Gel(5):G might be effective wound dressing material.

\section{Acknowledgement}

This research was supported by the Department of Biochemistry and Molecular Biology, Jahangirnagar University, Savar, Dhaka-1342, Bangladesh \& Bangladesh Council of Scientific and Industrial Research (BCSIR) Laboratories, Dhaka-1205; Bangladesh.

\section{Conflict of interest}

The authors do not declare any competing interest.

\section{References}

Alupei, I. C., Popa, M., Hamcerencu, M., \& Abadie, M. J. M. (2002). Superabsorbent hydrogels based on xanthan and poly (vinyl alcohol): the study of the swelling properties. Eur. Polym. J.38, 2313-2320. https://doi.org/10.1016/S0014-3057(02)00106-4

Bhattacharya, S. S., Mishra, A., Pal, D., Ghosh, A. K., Ghosh, A., Banerjee, S., \& Sen, K. K. (2012). Synthesis and characterization of poly (acrylic acid)/poly(vinyl alcohol)- xanthan gum interpenetrating network (IPN) superabsorbent polymeric composites. Polym. Plast. Technol. Eng. 51, 878-884. https://doi.org/10.1080/03602559.2012.671421

Bhunia, T., Giri, A., Nasim, T., Chattopadhyay, D., \& Bandyopadhyay, A. (2013). Uniquely different PVA-xanthan gum irradiated membranes as transdermal diltiazem delivery device. Carbohydr. Polym. 95,252-261. https://doi.org/10.1016/j.carbpol.2013.02.043 
Brunchi, C. E., Bercea, M., Morariu, S., \& Avadanei, M. (2016). Investigations on the interactions between xanthan gum and poly (vinyl alcohol) in solid state and aqueous solutions. Eur. Polym. J., 84, 161-172. https://doi.org/10.1016/j.eurpolymj.2016.09.006

Bueno, V. B., Bentini, R., Catalani, L. H., \& Petri, D. F. (2013). Synthesis and swelling behavior of xanthan-based hydrogels. Carbohydr. Polym. 92, 1091-1099. https://doi.org/10.1016/j.carbpol.2012.10.062

Camci-Unal, G., Cuttica, D., Annabi, N., Demarchi, D., \& Khademhosseini, A. (2013). Synthesis and characterization of hybrid hyaluronic acid-gelatin hydrogels. Biomacromolecules, 14, 1085-1092. https://doi.org/10.1021/bm3019856

Cartotto, R. (2017). Topical antimicrobial agents for pediatric burns. Burns Trauma, 5, 33. https://doi.org/10.1186/s41038-017-0096-6

Chavda, H. V., Patel, R. D., Modhia, I. P., \& Patel, C. N. (2012). Preparation and characterization of super porous hydrogel based on different polymers. Int. J. Pharm. Investig. 2, 134-139. https://doi.org/10.4103/2230973X.104396

Choi, Y. S., Hong, S. R., Lee, Y. M., Song, K. W., Park, M. H., \& Nam, Y. S. (1999). Study on gelatin-containing artificial skin: I. Preparation and characteristics of novel gelatin-alginate sponge. Biomaterials, 20, 409-417. https://doi.org/10.1016/S0142-9612(98)00180-X

Colón, J., Ruggieri, L., Sánchez, A., González, A., \& Puig, I. (2011). Possibilities of composting disposable diapers with municipal solid wastes. Waste Manag. Res. 29, 249-259. https://doi.org/10.1177/0734242X10364684

Davidson, R. L. (1980). Handbook of water-soluble gums and resins. McGraw-Hill: New York.

Disha, J. S., Begum, M. H. A., Shawan, M. M. A. K., Khatun, N., Ahmed, S., Islam, M. S., Karim, M. R., Islam, M. R., Hossain, M. M., \& Hasan, M. A. (2016). Preparation and Characterization of Xanthan Gum-based Biodegradable Polysaccharide Hydrogels. Research Journal of Material Sciences, 4, 13-18.

El-Kased, R. F., Amer, R. I., Attia, D., \& Elmazar, M. M. (2017). Honey-based hydrogel: In vitro and comparative In vivo evaluation for burn wound healing. Sci. Rep. 7, 9692. https://doi.org/10.1038/s41598-017-08771-8

El-Sherbiny, I. M., \& Yacoub, M. H. (2013). Hydrogel scaffolds for tissue engineering: Progress and challenges. Glob. Cardiol. Sci. Pract. 3, 316-342. https://doi.org/10.5339/gcsp.2013.38

Fan, L., Tan, C., Wang, L., Pan, X., Cao, M., Wen, F., Xie, W., \& Nie, M. (2013). Preparation, characterization and the effect of carboxymethylated chitosan-cellulose derivatives hydrogels on wound healing. J. Appl. Polym. Sci. 128, 2789-2786. https://doi.org/10.1002/app.38456

Fitzpatrick, P., Meadows, J., Ratcliffe, I., \& Williams, P. A. (2013). Control of the properties of xanthan/glucomannan mixed gels by varying xanthan fine structure. Carbohydr. Polym. 92, 1018-1025. https://doi.org/10.1016/j.carbpol.2012.10.049

García-Ochoa, F., Santos, V. E., Casas, J. A., \& Gómez, E. (2000). Xanthan gum: production, recovery, and properties. Biotechnol. Adv. 18, 549-579. https://doi.org/10.1016/S0734-9750(00)00050-1

Gu, H., Yue, Z., Leong, W. S., Nugraha, B., \& Tan, L. P. (2010). Control of in vitro neural differentiation of mesenchymal stem cells in 3D macroporous, cellulosic hydrogels. Regen Med. 5, 245-253. https://doi.org/10.2217/rme.09.89

Guan, J., Fujimoto, K. L., Sacks, M. S., \& Wagner, W. R. (2005). Preparation and characterization of highly porous, biodegradable polyurethane scaffolds for soft tissue applications. Biomaterials, 26, 3961-3971. https://doi.org/10.1016/j.biomaterials.2004.10.018

Guest, J. F., Ayoub, N., McIlwraith, T., Uchegbu, I., Gerrish, A., Weidlich, D., Vowden, K., \& Vowden, P. (2017). Health economic burden that different wound types impose on the UK's National Health Service. Int. Wound $J ., 14,322-330$. https://doi.org/10.1111/iwj.12603

Gupta, B., Agarwal, R., \& Alam, M. S. (2011). Biomedical Hydrogels, Biochemistry, Manufacture and Medical Applications, Rimmer, S., Eds., Woodhead Publishing Limited: Cambridge. Chapter 9, pp 184-227.

Hoffman, A. S. (2002). Hydrogels for biomedical applications. Adv. Drug. Deliv. Rev. 54, 3-12. https://doi.org/10.1016/j.addr.2012.09.010

Huglin, M. R. (1986). Hydrogels in Medicine and Pharmacy: Properties and Applications, Peppas, N. A., Eds. CRC Press, Llc: USA, pp 184.

Jayakumar, R., Menon, D., Manzoor, K., Nair, S. V., \& Tamura, H. (2010). Biomedical applications of chitin and 
chitosan based nanomaterials-A short review. Carbohydr. Polym, 82, 227-232. https://doi.org/10.1016/j.carbpol.2010.04.074

Jayakumar, R., Prabaharan, M., Nair, S. V., \& Tamura, H. (2010). Novel chitin and chitosan nanofibers in biomedical applications. Biotechnol. Adv., 28, 142-150. https://doi.org/10.1016/j.biotechadv.2009.11.001

Juris, S. J., Mueller, A., Smith, B., Johnston, S., Walker, R., \& Kross, R. (2011). Biodegradable Polysaccharide Gels for Skin Scaffolds. Journal of Biomaterials and Nanobiotechnology, 2, 216225.https://doi.org/10.4236/jbnb.2011.23027

Kamoun, E. A., Kenawy, E.-R. S., \& Chen, X. (2017). A review on polymeric hydrogel membranes for wound dressing applications: PVA-based hydrogel dressings. $J . A_{d v}$ Res. 8, 217-233. https://doi.org/10.1016/j.jare.2017.01.005

Karadağ, E., Ödemiş, H., Kundakçi, S., \& Üzüm, Ö. B. (2015). Swelling Characterization of Acrylamide/Zinc Acrylate/Xanthan Gum/Sepiolite Hybrid Hydrogels and Its Application in Sorption of Janus Green B from Aqueous Solutions. Adv. Polym. Technol. 35, 248-259. https://doi.org/10.1002/adv.21547

Kimura, Y., Ozeki, M., Inamoto, T., \& Tabata, Y. (2003). Adipose tissue engineering based on human preadipocytes combined with gelatin microspheres containing basic fibroblast growth factor. Biomaterials, 24, 2513-2521. https://doi.org/10.1016/S0142-9612(03)00049-8

Kommareddy, S., \& Amiji, M. (2005). Preparation and evaluation of thiol-modified gelatin nanoparticles for intracellular DNA delivery in response to glutathione. Bioconjug. Chem. 16, 1423-1432. https://doi.org/10.1021/bc050146t

Langer, R., \& Vacanti, J. P. (1993). Tissue engineering. Science, 260, 920-926. https://doi.org/10.1126/science.8493529

Lee, S. B., Jeon, H. W., Lee, Y. W., Lee, Y. M., Song, K. W., Park, M. H., Nam, Y. S., \& Ahn, H. C. (2003). Bioartificial skin composed of gelatin and (1->3),(1->6)-beta-glucan. Biomaterials, 24, 2503-2511. https://doi.org/10.1016/S0142-9612(03)00003-6

Li, D., Sun, H., Jiang, L., Zhang, K., Liu, W., Zhu, Y., Fangteng, J., Shi, C., Zhao, L., Sun, H., \& Yang, B. (2014). Enhanced biocompatibility of PLGA nanofibers with gelatin/nano-hydroxyapatite bone biomimetics incorporation. ACS Appl. Mater. Interfaces, 6, 9402-9410. https://doi.org/10.1021/am5017792

Liu, H., Yin, Y., \& Yao, K. J. (2007). Construction of chitosan-gelatin-hyaluronic acid artificial skin in vitro. Biomater. Appl. 21, 413-430.https://doi.org/10.1177/0885328206065241

Lu, G., Ling, K., Zhao, P., Xu, Z., Deng, C., Zheng, H., Huang, J., \& Chen, J. (2010). A novel in situ formed hydrogel wound dressing by the photocross linking of a chitosan derivative. Wound Repair Regen. 18, 70-79. https://doi.org/10.1111/j.1524-475X.2009.00557.x

Maden, S., Çal Kkoğlu, E., \& Bodamyal Zade, P. (2018). Hot Topics in Burn Injuries. Intechopen, Chapter 5, pp 7586.

Meyer-Ingold, W. (1993). Wound therapy: growth factors as agents to promote healing. Trends Biotechnol. 11, 387-392. https://doi.org/10.1016/0167-7799(93)90098-T

Pal, K., Banthia, A. K., \& Majumdar, D. K. (2009). Polymeric Hydrogels: Characterization and Biomedical Applications. Des. Monomers Polym. 12, 197-220. https://doi.org/10.1163/156855509X436030

Patel, A., \& Mequanint, K. (2011). Biomedical Engineering-Frontiers and Challenges, Fazel-Rezai, R., Eds., InTech OpenAccess Publisher: Croatia. Chapter 14, pp 275-296.

Pezeshki-Modaress, M., Zandi, M., \& Mirzadeh, H. (2014). Fabrication of gelatin/chitosan nanofibrous scaffold: process optimization and empirical modeling. Polymer Int. 64, 571-580. https://doi.org/10.1002/pi.4843

Pezeshki-Modaress, M., Zandi, M., \& Mirzadeh, H. (2015). Gelatin-GAG electrospun nanofibrous scaffold for skin tissue engineering: Fabrication and modeling of process parameters. Mater. Sci. Eng. C. Mater. Biol. Appl. 48, 704-712. https://doi.org/10.1016/j.msec.2014.12.023

Qui, Y., \& Park, K. (2001). Environment-sensitive hydrogels for drug delivery. Adv. Drug. Deliv. Rev., 53, 321339. https://doi.org/10.1016/S0169-409X(01)00203-4

Ray, M., Pal, K., Anis, A., \& Banthia, A. K. (2010). Development and Characterization of Chitosan-Based Polymeric Hydrogel Membranes. Des. Monomers Polym. 13, 193-206. https://doi.org/10.1163/138577210X12634696333479 
Ray, S., Banerjee, S., Maiti, S., Laha, B., Barik, S., Sa, B., \& Bhattacharyya, U. K. (2010). Novel interpenetrating network microspheres of xanthan gum-poly(vinyl alcohol) for the delivery of diclofenac sodium to the intestine-in vitro and in vivo evaluation. Drug Deliv. 17, 508-519. https://doi.org/10.3109/10717544.2010.483256

Rithe, S. S., Kadam, P. G., \& Mhaske, S. T. (2014). Preparation and Analysis of Novel Hydrogels Prepared from the Blend of Guar Gum and Chitosan: Cross-Linked With Glutaraldehyde. Advances in Materials Science and Engineering: An International Journal (MSEJ), 1.

Rozaini, M. Z., Zuki, A. B. Z., Noordin, M., Norimah, Y., \& Hakim, A. N. (2004). The Effects of Different Types of Honey on Tensile Strength Evaluation of Burn Wound Tissue Healing. Intern.J. Appl. Res. Vet. Med. 2, 290-296.

Schmidt, C. E., \& Leach, J. B. (2003). Neural tissue engineering: strategies for repair and regeneration. Annu. Rev. Biomed. Eng. 5, 293-347. https://doi.org/10.1146/annurev.bioeng.5.011303.120731

Varghese, S., Hwang N. S., Canver, A. C., Theprungsirikul, P., Lin, D. W., \& Elisseeff, J. (2008). Chondroitin sulfate based niches for chondrogenic differentiation of mesenchymal stem cells. Matrix Biol., 27, 12-21. https://doi.org/10.1016/j.matbio.2007.07.002

Varghese, S., Lele, A. K., \& Mashelkar, R. A. (2000). Designing new thermoreversible gels by molecular tailoring of hydrophilic-hydrophobic interactions. J. Chem. Phys., 112, 3063-3070. https://doi.org/10.1063/1.480881

Vladimir, M., Gun'ko, Savina, I. N., \& Mikhalovsky, S. V. (2017). Properties of Water Bound in Hydrogels. Gels 3. https://doi.org/10.3390/gels3040037

Vlierberghe, S. V., Dubruel, P., \& Schacht, E. (2011). Biopolymer-based hydrogels as scaffolds for tissue engineering applications: a review. Biomacromolecules, 12, 1387-1408. https://doi.org/10.1021/bm200083n

Walther, H., Lorentz, H., Kay, L., Heynen, M., \& Jones, L. (2011). The effect of in vitro lipid concentration on lipid deposition on silicone hydrogel and conventional hydrogel contact lens materials. Cont. Lens. Anterior Eye, 34, S21. https://doi.org/10.1016/S1367-0484(11)60099-4

Wei, Y., \& Durian, D. J. (2013). Effect of hydrogel particle additives on water-accessible pore structure of sandy soils: A custom pressure plate apparatus and capillary bundle model. Phys. Rev. E 87, 10 . https://doi.org/10.1103/PhysRevE.87.053013

Weller, C. (2009). Advanced Textiles for Wound Care, Rajendran, S., Eds., Woodhead Publishing Series in Textiles: Cambridge. Chapter 4, pp 97-113.

Weller, C., \& Sussman, G. (2006). Wound Dressing Update. J. Res. Pharm. Pract. 36, 318-324. https://doi.org/10.1002/j.2055-2335.2006.tb00640.x

Winter, G. D. (1962). Formation of the Scab and the Rate of Epithelization of Superficial Wounds in the Skin of the Young Domestic Pig. Nature, 193, 293-294. Retrieved from https://www.nature.com/articles/193293a0

Winter, G. D. (1972). Epidermal Wound Healing, In: Maibach, H. I. and Rovee. D. T., Eds. Year Book Medical Publishers: Chicago, pp 71-112.

Winter, G. D., \& Scales, J. T. (1963). Effect of air drying and dressings on the surface of a wound. Nature, 197, 91-92. Retrieved from https://www.nature.com/articles/197091b0

Wu, S., Deng, L., Hsia, H., Xu, K., He, Y., Huang, Q., Peng, Y., Zhou, Z., \& Peng, C. (2017). Evaluation of gelatinhyaluronic acid composite hydrogels for accelerating wound healing. J. Biomater. Appl. 31, 1380-1390. https://doi.org/10.1177/0885328217702526

Zhang, R., Huang, Z., Xue, M., Yang, J., \& Tan, T. (2011). Detailed characterization of an injectable hyaluronic acid-polyaspartylhydrazide hydrogel for protein delivery. Carbohydr. Polym, 85, 717-725. https://doi.org/10.1016/j.carbpol.2011.02.014

\section{Copyrights}

Copyright for this article is retained by the author(s), with first publication rights granted to the journal.

This is an open-access article distributed under the terms and conditions of the Creative Commons Attribution license (http://creativecommons.org/licenses/by/4.0/). 